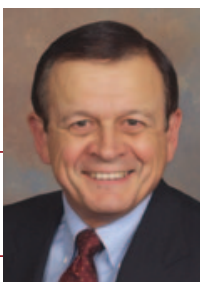

In 2010, the world's largest annual microscopy meeting and instrument exhibition, Microscopy \& Microanalysis, will be held August 1-5 in Portland, Oregon. This delightful meeting location was the site for our successful 1999 M\&M meeting, and we return to Portland by popular demand.

This is an extraordinary time for microscopy and microanalysis. At no time in my memory were there such exciting technical developments and new products: advanced methods in light microscopy, new applications of scanning probe microscopy, aberrationcorrected EM, ultra-fast EM, focused ion-beam methods, atom probe tomography, silicon-drift x-ray detectors, and analytical data acquisition by spectrum imaging. As always, the place to hear about and see these developments is the M\&M meeting.

Remember the Deadline! Extended abstracts for platform and poster presentations are due by Monday, February $\mathbf{1 5}^{\text {th }}, \mathbf{2 0 1 0}$. This hard deadline is necessary in order to produce a complete compilation of extended abstracts in time for the meeting. This year all abstracts will be on a DVD-ROM provided to each full-meeting registrant. While shorter abstracts are allowed, the opportunity to lay out a summary of your presentation in the traditional Microscopy \& Microanalysis two-page abstract format with color figures, graphs, and diagrams on the second page is a distinct advantage.

To view the broad range of topics for the 34 special symposia, go to the MSA website, http://www.microscopy.org, and find the M\&M2010 button. This leads you to the meeting site where you can locate all you need to know about the meeting: the Call for Papers, submission details, registration and hotel information, and fun things to do in and around Portland. The opening plenary presentation, "What Microscopy Can Tell Us about Alzheimer's and Related Diseases," will be given by Professor Mark Welland of the Nanoscience Centre at the University of Cambridge in the UK. This talk will highlight the use of scanned probe microscopies to fight disease.

If you can't find what you need on the website, contact the program chair, John Mansfield (jfmjfm@umich.edu), and he will do his best to help you. John Mansfield describes additional features of M\&M 2010 on page 38. Plan now to attend this important meeting. Don't miss it.

\section{Charles Lyman}

Editor-in-Chief

\section{Publication Objective: to provide information of interest to microscopists.}

Microscopy Today is a controlled-circulation trade magazine owned by the Microscopy Society of America that is published six times a year in the odd months. Editorial coverage spans all microscopy techniques including light microscopy, scanning probe microscopy, electron microscopy, ion-beam techniques, and the wide range of microanalytical methods. Readers and authors come from both the life sciences and the physical sciences. The typical length of an article is about 2,000 words plus figures and tables; feature articles are longer. Interested authors should consult "Instructions for Contributors" on the Microscopy Today website: www.microscopy-today.com.

\section{ISSN 1551-9295}

\section{Disclaimer}

The Microscopy Society of America and the editors cannot be held responsible for opinions, errors, or for any consequences arising from the use of information contained in Microscopy Today. The appearance of advertising in Microscopy Today does not constitute an endorsement or approval by the Microscopy Society of America of any claims or information found in the advertisements. By submitting a manuscript to Microscopy Today, the author warrants that the article is original or that the author has written permission to use copyrighted material published elsewhere. While the contents of this magazine are believed to be accurate at press time, neither the Microscopy Society of America, the editors, nor the authors can accept legal responsibility for errors or omissions.

(C) Copyright 2010 by the Microscopy Society of America. All rights reserved.

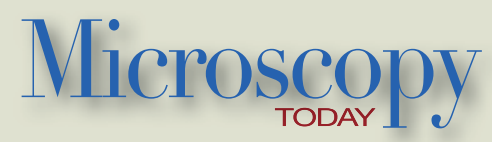

Editorial Staff

Charles E. Lyman

Editor-in-Chief

charles.lyman@lehigh.edu

(610) 758-4249

Gennifer Levey, Production Manager glevey@meridianartproduction.com (212) $780-0315$

Ron Anderson, Executive Editor microscopytoday@tampabay.rr.com

Phil Oshel, Technical Editor

oshel1pe@cmich.edu

Stephen Carmichael, Columnist carmichael.stephen@mayo.edu

Michael Davidson, Pioneers Editor davidson@magnet.fsu.edu

Steven Barlow, Education Editor

sbarlow@sunstroke.sdsu.edu

Thomas E. Phillips, Consulting Editor phillipst@missouri.edu

E. Ann Ellis, Microscopy 101 Editor eann.ellis@worldnet.att.net

John Shields, Humor Editor

jshields@cb.uga.edu

Advertising Sales

M.J. Mrvica Associates, Inc.

2 West Taunton Avenue, Berlin, NJ 08009 mjmrvica@mrvica.com

(856) 768-9360

Amy Reuter, Account Manager areuter@mrvica.com

Magazine website:

http://www.microscopy-today.com

Free subscriptions are available for qualifying individuals

Publisher

Cambridge University Press

32 Avenue of the Americas

New York, NY 10013-2473

(212) $337-5000$

Circulation: 16,400

\section{Editorial Board}

Arlan Benscoter, Lehigh University John Bozzola, Southern Illinois University Peter Crozier, Arizona State University Vinayak Dravid, Northwestern University Joseph Goldstein, University of Massachusetts Bryan Huey, University of Connecticut Thomas Kelly, Imago Corporation John Mackenzie, North Carolina State Univ. Ania Majewska, U. Rochester Med School Greg Meeker, U.S. Geological Survey Joseph Michael, Sandia National Labs Caroline Miller, Indiana University John Reffner, John Jay College, SUNY Ian Robertson, University of Illinois Phillip Russell, Appalachian State University Glenn Shipley, Citizen Microscopist Robert Simmons, Georgia State University Simon Watkins, University of Pittsburgh Paul Webster, House Ear Institute Paul Voyles, University of Wisconsin Cynthia Zeissler, Nat. Inst. of Sci. and Tech. (NIST) 